\title{
Evaluasi fasilitas fungsional pelabuhan perikanan pantai Bacan
}

\section{(Evaluation of functional facilities at the Bacan coastal fishing port)}

\author{
Irham $^{1}$, Kusdi Hi Iksan ${ }^{2}$, Hardin $^{3}$ \\ ${ }^{1}$ Program Studi MSP, Fakultas Perikanan dan Kelautan, Universitas Khairun Ternate. \\ E-mail: inon_kair@yahoo.co.id \\ ${ }^{2}$ Program Studi MSP, Fakultas Perikanan dan Kelautan, Universitas Khairun Ternate. \\ ${ }^{3}$ Program Studi TPI, Politeknik Halmahera.
}

Diterima: 6 Juni 2020; Disetujui: 30 Oktober 2020

\begin{abstract}
ABSTRAK
Pelabuhan perikanan pantai Bacan merupakan pusat kegiatan nelayan, pedagang dan pengolah ikan di kabupaten Halmahera Selatan.Keberhasilan operasional pelabuhan perikanan pantai Bacan tidak terlepas dari faktor-faktor pendukung yang ada, salah satunya adalah tersedinya fasilitas fungsional yang memadai.Penelitian ini bertujuan untuk menganalisis tingkat kepuasan pengguna fasilitas fungsional di pelabuhan perikanan pantai Bacan. Metode pengumpulan data menggunakan metode survey dan observasi dengan cara pengamatan langsung di lapangan, wawancara, dan pengisian kuisioner. Analisis data menggunakan customer satisfaction index (CSI) untuk mengetahui besarnya tingkat kepuasan nelayan, importance and performance analysis (IPA) untuk mengetahui atribut fungsi yang dianggap penting oleh nelayan, dan analisis kesenjangan untuk mempersepsikan pelayanan yang diterima konsumen.Hasil penelitian menunjukan bahwa terdapat sebanyak 13 unit fasilitas fungsionaldi pelabuhan perikanan pantai Bacan, namun yang memperoleh kategori baikdengan kondisi layak pakaihanya 10 unit.Adapun tingkat kepuasan fasilitas fungsional mencapai $83 \%$ dengan kategori puas.
\end{abstract}

Kata kunci: Evaluasi, fasilitas fungsional, pelabuhan perikanan pantai Bacan

\begin{abstract}
Bacan coastal fishing port is the center of fishermen, traders and fish processors activity in South Halmahera district. The operational success of the Bacan coastal fishing port is inseparable from the supporting factors that exist, one of which is the availability of adequate functional facilities. This study aims to analyze the level of satisfaction of users of functional facilities in the coastal fishing port of Bacan.Data collection methods using survey and observation methods by direct observation in the field, interviews, and filling out the questionnaire. Data analysis uses the customer satisfaction index (CSI) to determine the level of satisfaction of fishermen, importance and performance analysis (IPA) to determine the functional attributes that are considered important by fishermen, and gap analysis to perceive the services received by consumers. The results showed that there were as many as 13 units of functional facilities in the coastal fishing port of Bacan, but only 10 units received a good category with suitable condition. The satisfaction level of functional facilities reaches $83 \%$ with the satisfied category.
\end{abstract}

Keywords: Evaluation, functional facilities, Bacan coastal fishing port 

pantai Bacan, 3 (2) : 238 - 248

\section{Pendahuluan}

Keberhasilan operasional pelabuhan perikanan tidak terlepas dari semua faktorfaktor pendukung yang ada, salah satunya adalah tersedianya fasilitas pelabuhan perikanan.Fasilitas-fasilitas tersebut terdiri dari fasilitas pokok, fungsional, dan penunjang.Banyak pelabuhan tidak memiliki fasilitas yang memadai sehingga kurang melaksanakan fungsi-fungsinya secara optimal. Lubis (2006) mengemukakan bahwa terlaksana atau tidaknya fungsi-fungsi pelabuhan perikanan secara optimal, akan mengindikasikan tingkat keberhasilan pengelolaan suatu pelabuhan perikanan.Oleh karena itu, keberadaan dan kondisi fasilitas sangat perlu diperhatikan agar aktivitas yang terdapat di pelabuhan perikanan dapat berjalan dengan baik.

Pelabuhan perikanan dalam menjalankan fungsinya sebagai pusat pelayanan umum, dituntut untuk segera dapat menjalankan fungsinya dengan baik, namun di lain pihak masih didapatkan kelemahan-kelemahan dalam pemanfaatannya, baik yang diakibatkan oleh kualitas pengelola karena kurangnya pengalaman dalam mengelola pelabuhan perikanan, maupun hambatan operasional yang disebabkan oleh kurangnya fasilitas yang menyebabkan pelabuhan perikanan tidak dapat menjalankan fungsinya secara optimal (Ditjen Perikanan, 2002). Menurut Widiastuti (2010), dari berbagai fungsi yang sedemikian komplek, maka pelabuhan perikanan sebagai salah satu organisasi publik harus memenuhi kebutuhan dan melindungi kepentingan publik. Hal tersebut berkaitan dengan kinerja dalam hal pelayanan yang diberikan oleh pelabuhan perikanan terhadap penerima pelayanan.Pengukuran keberhasilan maupun kegagalan instansi pemerintah yang dalam hal ini "pelabuhan perikanan" dalam menjalankan tugas pokok dan fungsinya sebagai organisasi publik yang melayani masyarakat sulit dilakukansecara obyektif. Hal ini disebabkan oleh belum diterapkannya sistem pengukuran kinerja yang dapat menginformasikan tingkat keberhasilan secara obyektif dan terukur dari pelaksanaan program-program di suatu pelabuhan perikanan.

Pelabuhan Perikanan Pantai (PPP) Bacan sebagai Unit Pelaksana Tekhnis Dinas Kelautan dan Perikanan Provinsi Maluku Utara terletak di wilayah Kabupaten Halmahera Selatan, tepatnya berada di Desa Panamboang, Kecamatan Bacan Selatan, \pm $8 \mathrm{Km}$ arah selatan dari Kota Labuha, Ibu Kota Kabupaten Halmahera Selatan. Pelabuhan Perikanan Pantai (PPP) Bacan, terletak antara $0^{\circ} 41^{\prime} .51,2^{\prime \prime}$ LS dan $127^{\circ} 27^{\prime}$ 42,4" BT. Pelabuhan Perikanan Pantai (PPP) Bacan semula merupakan Pangkalan Pendaratan Ikan (PPI) yang dibangun pada tahun 1991 yang pengelolaannya semula di bawah Dinas Perikanan Kabupaten Maluku Utara Cabang Dinas Perikanan Maluku di Ambon.

Pelabuhan Perikanan Pantai (PPP) Bacan bergerak dalam kegiatan di bidang Perikanan tangkap, yang diperoleh hasil tangkapan para nelayan dengan jenis ikan potensial seperti cakalang, tuna, tongkol dan layang.Sejak kehadiran Pelabuhan Perikanan Pantai (PPP) Bacan di Kabupaten Halmahera Selatan dalam rangka memanfaatkan potensi alam khususnya perairan laut yang cukup menjanjikan, sehingga diharapkan mendukung program pemerintah pusat yang menjadikan perikanan sebagai sektor penting dalam mendongkrak perekonomian Indonesia.Dalam melaksanakan aktivitas operasinya, Pelabuhan Perikanan Pantai (PPP) Bacan dapat memperoleh hasil tangkapan ikan yang didaratkan oleh nelayan untuk mendapatkan keuntungan yang 
cukup menjanjikan tetapi harus pula didukung dengan fasilitas pelabuhan memadai salah satunya adalah fasilitas fungsional.

\section{Metode penelitian}

Penelitian ini dilaksanakan di pelabuhan perikanan pantai (PPP) Bacan kabupaten Halmahera Selatan dari bulan September hingga November 2019. Peta lokasi penelitian (Gambar 1).

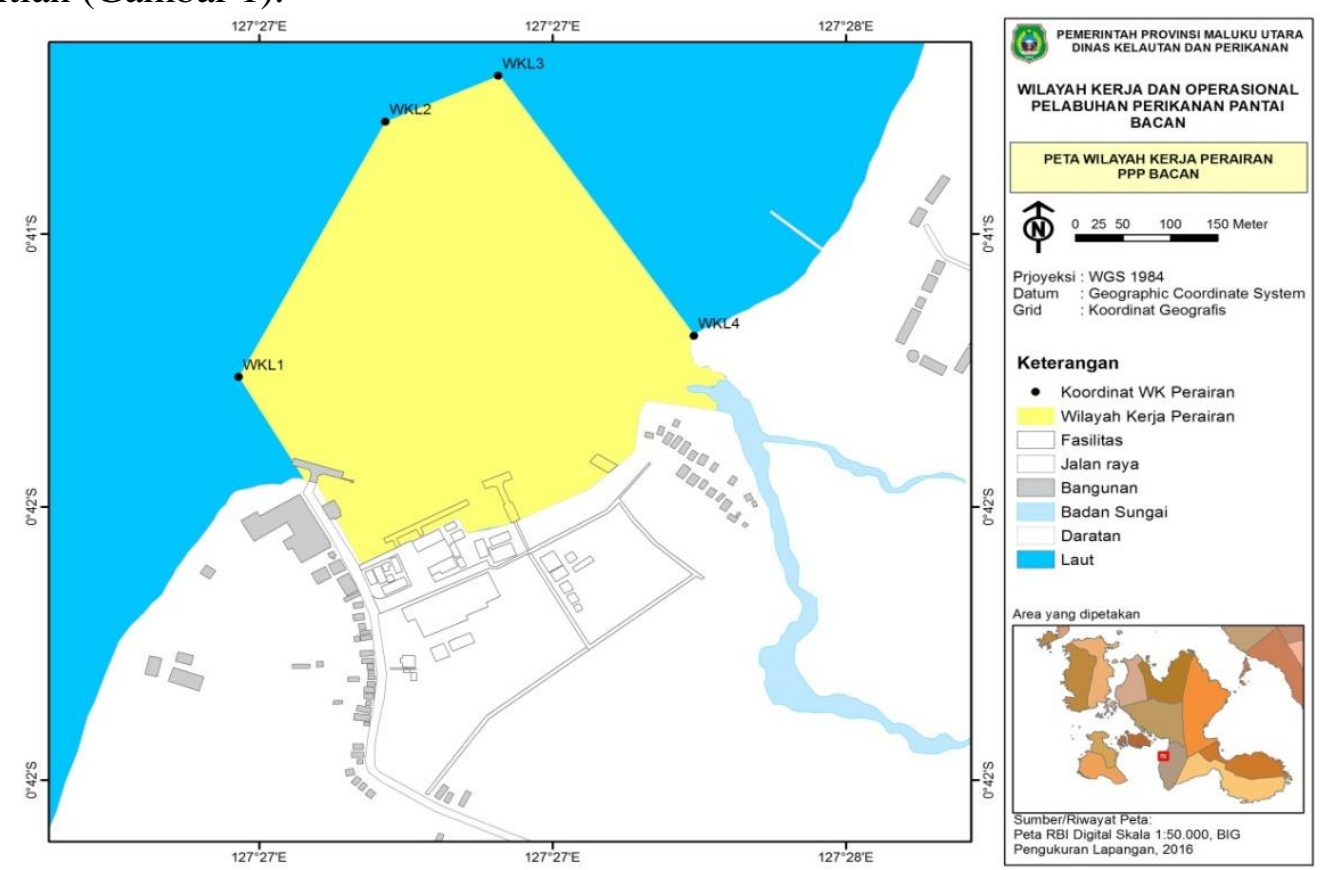

Gambar 1. Peta Lokasi Penelitian

Metode pengambilan data menggunakan metode survey dan observasi yaitu dengan cara pengamatan langsung di lapangan, wawancara, dan pengisian kuisioner. Data yang dikumpulkan terdiri dari data primer berupa keberadaan dan kondisi serta tingkat pemanfaatan dan kepuasan pengguna fasilitas yang adapelabuhan perikanan pantai Bacan.Analisis yang digunakan dalam menentukan tingkat kepuasan bagi nelayan yaitu:

- Customer Satisfaction Indeks (CSI) (Irawan, 2006),

Metode pengukuran CSI meliputi tahap-tahap sebagai berikut :

1. Menghitung Weighting Factor $(W F)$, diperoleh dari mengubah nilai rata-rata kepentingan menjadi angka persentase dari total rata-rata tingkat kepentingan seluruh atribut yang diuji dan dikalikan $100 \%$, sehingga diperoleh nilai keseluruhan WF yaitu $100 \%$.

2. Menghitung Weighted Scored (WS), yaitu nilai perkalian antar nilai rata-rata tingkat kinerja masing-masing atribut dengan WF masing-masing atribut.

3. Menghitung Weighted Total (WT), yaitu menjumlahkan WS dari semua atribut pelayanan, dan 
4. Menghitung Satisfaction Indeks (SI), yaitu WT dibagi (L) skala maksimal yang digunakan (dalam penelitian ini skala maksimum yang digunakan adalah 5), kemudian dikali $100 \%$.

Berdasarkan buku panduan survei kepuasan pelanggan dan pegawai PT Sucofindo dalam Atharis (2008), tingkat kepuasan secara keseluruhan dapat dilihat dari kriteria tingkat kepuasan pelanggan dan pegawai, dengan kriteria sebagai berikut:

0,00-0,34 : sangat tidak puas (pelayanan sangat tidak memenuhi kebutuhan pelanggan).

0,35-0,50 : tidak puas (pelayanan tidak memenuhi kebutuhan pelanggan).

0,51- 0,65: cukup puas (pelayanan cukup memenuhi kebutuhan pelanggan).

0,66 -0,80 : Puas (pelayanan sudah memenuhi kebutuhan pelanggan).

0,81-1,00 : sangat puas (pelayanan sangat memenuhi kebutuhan pelanggan).

\section{- Importance dan Performance Analysis (IPA)}

Metode analisis importance dan performance digunakan untuk mengetahui tingkat perbandingan skor kinerja dengan skor tingkat kepentingan yang kemudian akan menghasilkan faktor-faktor yang harus diambil dalam memenuhi kinerjanya (Supranto, 2001).

\section{- Analisis Kesenjangan (Gap Analysis)}

Nilai kesenjangan tersebut disesuaikan dengan selang kelas penilaian. Walpole (1997), mengemukakan bahwa untuk membuat selang kelas bagi segugusan data dapat dilakukan dengan langkah-langkah sebagai berikut:

1. Penentuan selang kelas sebanyak lima kelas yang terdiri atas kelas sangat puas, puas, cukup puas, kurang puas dan tidak puas terhadap dimensi dan variabel pelayanan pada penelitian ini.

2. Penentuan besar wilayah dengan mengurangi data terbesar dengan data terkecil.

3. Penentuan panjang kelas dengan membagi besar wilayah dengan banyaknya kelas.

4. Penentuan limit bawah kelas bagi selang pertama dan kemudian batas bawah kelasnya. Tambahkan panjang kelas pada batas bawah untuk mendapatkan batas atas pada kelas yang sama.

5. Daftarkan penentuan kelas berikutnya hingga data terbesar.

\section{Hasil dan pembahasan}

\section{Fasilitas fungsional pelabuhanperikanan pantai Bacan}

Kondisi fasilitas fungsional di pelabuhan perikanan pantai Bacan dapat dilihat pada tabel 1 berikut ini.

Tabel 1. Fasilitas fungsional pelabuhan perikanan pantai Bacan

\begin{tabular}{llccc}
\hline & Fasilitas fungsional & Volume & Satuan & Keterangan \\
\hline 1 & Tempat pemasaran ikan (TPI) & 470,47 & $\mathrm{~m}^{2}$ & Baik \\
\hline 2 & Internet & 10 & $\mathrm{~KB}$ & Baik \\
\hline 3 & Radio komunikasi & - & - & Tidak Berfungsi \\
\hline 4 & Air bersih & 50 & Ton & Baik \\
\hline 5 & Instalasi bahan bakar minyak (BBM) & 375 & $\mathrm{~m}^{2}$ & Baik \\
\hline 6 & Es & 1,25 & Ton & Baik \\
\hline 7 & Instalasi listrik & 2000 & KVA & Baik \\
\hline 8 & Dock/slipway & - & - & Tidak Berfungsi \\
\hline 9 & Bengkel & - & - & Tidak Berfungsi \\
\hline
\end{tabular}




\begin{tabular}{llccc}
10 & Kantor administrasi pelabuhan & 219,45 & $\mathrm{~m}^{2}$ & Baik \\
\hline 11 & Pos pelayanan terpadu & 163,16 & $\mathrm{~m}^{2}$ & Baik \\
\hline 12 & Alat-alat angkut ikan & 4 & unit & Baik \\
\hline 13 & Pagar pengawasan & 820 & $\mathrm{~m}^{2}$ & Baik \\
\hline
\end{tabular}

Fasilitas yang tidak dapat digunakan adalah radio komunikasi, dock/slipway dan bengkel. Fasilitas tersebut tidak dapat digunakan dikarenakan dalam kondisi rusak, namun sama sekali tidak mengganggu aktivitas kepelabuhanan. Hal ini dikarenakan fasilitas tersebut mengalami kerusakan saat dilakukan pemindahan pada tempat yang baru dan belum tersedianya biaya operasional untuk perbaikan.

Dari kategori yang diperoleh dapat disimpulkan bahwa secara umum kondisi fasilitas fungsional di Pelabuhan Perikanan Pantai (PPP) Bacan berada pada kategori baik.Hal ini didasarkan pada kondisi yang menunjukkan bahwa secara umum fasilitas fungsional dalam menunjang aktivitas di Pelabuhan Perikanan Pantai (PPP) Bacan berjalan dengan baik.

Berdasarkan tabel diatas menunjukkan bahwa tingkat kebutuhan fasilitas fungsional Pelabuhan Perikanan Pantai (PPP) sudah mencapai daya guna yang optimal, hal ini terlihat dari tingkat pemanfaatan $=100 \%$ sehingga fasilitas fungsional Pelabuhan Perikanan Pantai (PPP) sangat baik untuk melayani kegiatan operasional perikanan tangkap di Pelabuhan Perikanan Pantai (PPP) Bacan. Hal ini sesuai dengan pendapat Soedjono (1985), menyatakan bahwa persentasi pemanfaatan $=100 \%$ artinya tingkat pendayagunaan fasilitas mencapai kondisi optimal.

Sementara Mustari dan Dahri (2011), mengatakan bahwa tingkat optimalisasi 80,01\%-100\% artinya tingkat optimalisasi sangat baik. Hal ini dikarenakan seluruh fasilitas yang tersedia di Pelabuhan Perikanan Pantai (PPP) Bacan sudah digunakan seluruhnya sesuai dengan kapasitas yang tersedia.

\section{Tingkat kepuasan pengguna}

\section{a) Customer satisfaction indeks (CSI)}

Tingkat kesesuaian terhadap kepuasan nelayan, tengkulak, dan pegawai di pelabuhan perikanan pantai Bacan dapat dilihat pada tabel 2.

Tabel 2. Tingkat kesesuaian terhadap kepuasan nelayan, tengkulak,dan pegawai

\begin{tabular}{clc}
\hline No & \multicolumn{1}{c}{ Fasilitas fungsional } & Tingkat kesesuaian (\%) \\
\hline 1 & Tempat pemasaran ikan (TPI) & 80,1 \\
\hline 2 & Internet & 86,8 \\
\hline 3 & Air bersih & 83,5 \\
\hline 4 & Instalasi bahan bakar minyak (BBM) & 77,8 \\
\hline 5 & Es & 81,7 \\
\hline 6 & Instalasi listrik & 86,4 \\
\hline 7 & Kantor administrasi pelabuhan & 78,8 \\
\hline 8 & Pos pelayanan terpadu & 72,1 \\
\hline
\end{tabular}


ricle.

\begin{tabular}{clc}
9 & Alat-alat angkut ikan & 75,6 \\
\hline 10 & Pagar pengawasan & 79,8 \\
\hline & Rata-rata Persentasi & 80,3
\end{tabular}

Berdasarkan hasil perhitungan pada tabel 2, nilai tingkat kesesuaian terhadap kepuasan nelayan, tengkulak, dan pegawai dengan kategori sangat puasyaitu internet $(86,8 \%)$, instalasi listrik $(86,4 \%)$, air bersih $(83,5 \%)$, es $(81,7 \%)$, dan tempat pemasaran ikan (TPI) $(80,1 \%)$. Hal ini dikarenakan kelima fasilitas tersebut dianggap sangat baik pelayanannya dalam menunjang aktivitas di pelabuhan perikanan pantai Bacan. Sementara itu, fasilitas dengan kategori puasyaitu pos pelayanan terpadu $(72,1 \%)$, alat-alat angkut ikan $(75,6 \%)$, instalasi bahan bakar minyak (BBM) (77,8\%), kantor administrasi pelabuhan $(78,8 \%)$, dan pagar pengawasan $(79,8 \%)$. Hal tersebut menunjukan bahwa keberadaan fasilitas tersebut dianggap memuaskan pelayanannya bagi para nelayan, tengkulak, dan pegawai.Secara umum, semua fasilitas tersebut sangat membantu aktivitas para nelayan, tengkulak, dan pegawai.Selain itu, pula harapan dari para pengguna fasilitas tersebut agar fasilitas yang belum ada namun diperlukan (BANP) agar dapat direalisasikan keberadaannya sehingga aktivitas kepelabuhanan dapat berjalan maksimal. Di Pelabuhan Perikanan Pantai (PPP) Bacan, fasilitas yang kebutuhannya belum ada namun diperlukan (BANP) adalah rambu-rambu, lampu suar, menara pengawas, tempat perbaikan jaring, dan laboratorium pembinaan mutu. Fasilitas sistem rambu-rambu harus segera direalisasikan pengadaannya mengingat fasilitas ini dibutuhkan untuk mengatur alur masuk kapal dan menghindari tabrakan.

Guswanto, et al (2012), menyatakan bahwa terciptanya suatu pelayanan yang baik merupakan suatu hal yang mutlak di pelabuhan perikanan dan harus diusahakan, karena pelayanan merupakan salah suatu kegiatan yang menentukan keberhasilan pengembangan pembangunan pelabuhan perikanan.

\section{b) Importance and performance analysis (IPA)}

Keberhasilanpihak pengelola pelabuhan perikanan pantaiBacan dalam memuaskan nelayan dengan memberikan pelayanan kebutuhan operasional penangkapan ikanyang berkualitas bukanlah suatu hasil yang dapat membuat pihak pengelola pelabuhan cepat merasakan puas dan berhenti dalam mengembangkan kualitas pelayanan yang diberikan.

Pihak pengelola pelabuhan harus tetap terus memperhatikan pelayanan yang diberikan, fasilitas apa yang sekiranya dinilai penting bagi nelayan dan perlu ditingkatkan kinerjanya, pelayanan apa yang seharusnya tetap dipertahankan kualitasnya. Selain itu, pihak pengelola pelabuhan harus bisa menentukan pengelolaan pelayanan yang tepat yang harus dilakukan dengan segera.Pengelolaan pelayanan yang tepat dapat dianalisis dengan menggunakan Importance and Performance Analysis (IPA). Perhitungan importance and performance analysis (IPA) dan pembuatan diagram kartesius dilakukan dengan menggunakan program Microsoft Office Excel 2010. Berikut indeks importance and performance atribut pelayanan kebutuhan fasilitas dapat dilihat pada tabel 3 .

Tabel 3. Indeks importance and performance atribut pelayanan kebutuhan fasilitas

\begin{tabular}{cccc}
\hline No & Fasilitas fungsional & Indeks kinerja & $\begin{array}{c}\text { Indeks } \\
\text { kepentingan }\end{array}$ \\
\hline 1 & Tempat pemasaran ikan (TPI) & 1,00 & 1,00 \\
\hline
\end{tabular}




\begin{tabular}{clll}
2 & Internet & 1,00 & 1,00 \\
\hline 3 & Air bersih & 1,00 & 1,00 \\
\hline 4 & Instalasi bahan bakar minyak (BBM) & 1,00 & 1,00 \\
\hline 5 & Es & 1,00 & 1,00 \\
\hline 6 & Instalasi listrik & 1,00 & 1,00 \\
\hline 7 & Kantor administrasi pelabuhan & 1,00 & 1,00 \\
\hline 8 & Pos pelayanan terpadu & 1,00 & 1,00 \\
\hline 9 & Alat-alat angkut ikan & 1,00 & 1,00 \\
\hline 10 & Pagar pengawasan & 1,00 & 1,00 \\
\hline Rata-rata indeks & 1,00 & 1,00 \\
\hline
\end{tabular}

Atribut pelayanan kebutuhan fasilitas fungsional yang tersedia di pelabuhan perikanan pantai Bacan sangat mendukung aktvitas bagi para nelayan, tengkulak dan pegawai dalam memanfaatkan fasilitas tersebut.Berdasarkan hasil penelitian ada sekitar 10 dari 13 fasilitas fungsional yang tersedia di pelabuhan perikanan pantai Bacan. Hasil perhitungan dari indeks kinerja dan indeks kepentingan memperoleh nilai rata-rata 1,00. Hal tersebut menunjukan bahwa keberadaan fasilitas tersebut sangat baik pelayanannya dengan kategori sangat puas dalam memenuhi kebutuhan aktivitas bagi para nelayan, tengkulak maupun pegawai di lingkup pelabuhan perikanan pantai Bacan. Pihak pelabuhan perikanan pantai Bacan berupaya agar kedepannya fasilitas yang belum tersedia segera direalisasikan keberadaannya, terutama untuk fasilitas belum ada namun diperlukan (BANP), salah satunya menjadi prioritas adalah rambu-rambu, karena berkaitan dengan keselamatan para nelayan untuk menghindari tabrakan kapal. Berikut ini merupakan tampilan diagram kartesius pada fasilitas fungsional yang tersedia dengan kondisi layak pakai(Gambar 2).

\section{Y}

Tempat pemasaran

Internet

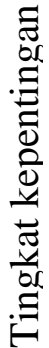

Air

Instalasi listrik

Es

Kantor adm. Pelabuhan

Pos pelayanan

Alat-alat angkut ikan

Pagar pengawasan 


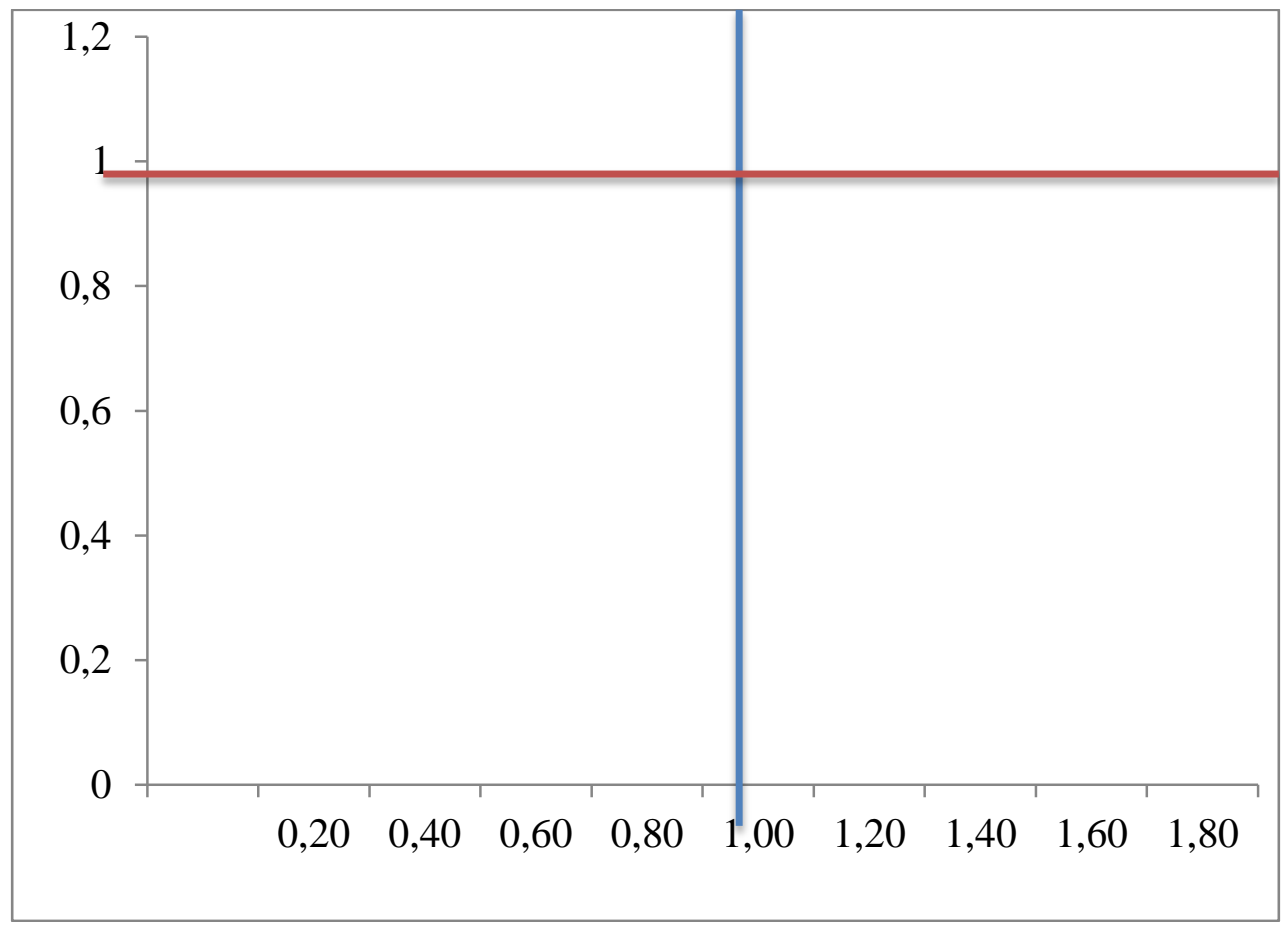

Gambar 2. .Diagram kartesius importance and performance atributpelayanan kebutuhan fasilitas

\section{Kuadran I}

Berdasarkan hasil perhitungan diagram kartesius, tidak terdapat fasilitas yang masuk pada kuadran I atau yang menjadi prioritas utama bagi pihak pelabuhan untuk perbaikan. Hal tersebut dikarenakan fasilitas yang tersedia semua dalam kondisi layak pakai dan menunjang aktivitas di pelabuhan perikanan pantai Bacan dengan baik dan lancar.

\section{Kuadran II}

Pada kuadran II atau yang menjadi keunggulan dan kekuatan pihak pelabuhan, tidak ada satu pun fasilitas fungsional yang tersedia masuk pada kuadran tersebut.Hal ini dikarenakan seluruh fasilitas yang tersedia semuanya dianggap penting dalam menunjang aktivitas kepelabuhanan dalam melayani kegiatan nelayan, tengkulak, dan pegawai.Lubis (2011), mengemukakan bahwa fungsi utama pelabuhan perikanan adalah berkaitan dengan pelayanan jasa-jasa untuk kapal-kapal yang telah selesai menangkap ikan dari daerah penangkapan (contoh adanya fasilitas pendaratan ikan yang aman dan pemeliharaan kapal). Ketersediaan jumlah petugas pelabuhan sudah memenuhi kebutuhan sehingga pada saat nelayan akan melakukan pelayanan bisa langsung ditangani oleh petugas pelabuhan.

\section{Kuadran III}

Atribut pelayanan kebutuhan yang termasuk ke dalam kuadran III atau yang menjadi prioritas rendah untuk dilakukan perbaikan adalah seluruh fasilitas yang tersedia yaitu fasilitas tempat pemasaran ikan (TPI), internet, air bersih, instalasi bahan bakar minyak (BBM), es, instalasi listrik, kantor administrasi pelabuhaan, pos pelayanan terpadu, alat-alat angkut ikan, dan pagar pengawasan. Hal ini dikarenakan 
keseluruhan fasilitas tersebut dalam kondisi layak pakai dalam menunjang aktivitas kepelabuhanan.

Soamole dan Bendiktus (2013), mengemukakan bahwa atribut pada kuadran III memiliki kualitas jasa pelayanan yang dianggap kurang penting pengaruhnya bagi pelanggan dan kinerja penyedia jasa biasa-biasa saja sehingga pengguna jasa merasa tidak puas dengan pelayanan yang diberikan.Berdasarkan analisis atribut-atribut ini dianggap tidak terlalu penting karena nelayan menganggap atribut ini biasa saja.

\section{Kuadran IV}

Sementara itu, tidak ada fasilitas yang masuk dalam atribut pelayanan yang dinilai berlebihan dalam pelaksanaannya atau yang termasuk ke dalam kuadran IV.Hal ini karena fasilitas dapat menunjang dengan aktivitas di pelabuhan perikanan pantai Bacan.Aryani dan Rosinta (2010), menyatakan bahwa semakin tinggi kualitas layanan suatu perusahaan semakin tinggi pula kepuasan yang diterima oleh pelanggan.

\section{c)Tingkatkesenjangan (Gap)}

Tingkat kesenjangan fasilitas fungsional di pelabuhan perikanan pantai Bacan dapat dilihat pada tabel 4:

Tabel 4. Hasil perhitungan analisis kesenjangan atribut pelayanan penyediaan kebutuhan fasilitas.

\begin{tabular}{llcc}
\hline No & \multicolumn{1}{c}{ Fasilitas fngsional } & $\begin{array}{c}\text { Tingkat } \\
\text { kesenjangan }\end{array}$ & keterangan \\
\hline 1 & Tempat pemasaran ikan (TPI) & 0,00 & Tidak Puas \\
\hline 2 & Internet & 0,00 & Tidak Puas \\
\hline 3 & Air Bersih & 0,00 & Tidak Puas \\
\hline 4 & $\begin{array}{l}\text { Instalasi bahan bakar minyak } \\
\text { (BBM) }\end{array}$ & 0,00 & Tidak Puas \\
\hline 5 & Es & 0,00 & Tidak Puas \\
\hline 6 & Instalasi listrik & 0,00 & Tidak Puas \\
\hline 7 & Kantor administrasi pelabuhan & 0,00 & Tidak Puas \\
\hline 8 & Pos pelayanan terpadu & 0,00 & Tidak Puas \\
\hline 9 & Alat-alat angkut ikan & 0,00 & Tidak Puas \\
\hline 10 & Pagar pengawasan & 0,00 & Tidak Puas \\
\hline
\end{tabular}

Hasil perhitungan dalam penelitian ini menunjukan bahwa tingkat kesenjangan dari seluruh fungsional yang tersedia di pelabuhan perikanan pantai Bacan memiliki nilai 0,00 dengan kategori Tidak Puas. Hal ini dikarenakan antara indeks kinerja dan indeks kepentingan memiliki nilai yang sama yaitu 1,00. Oleh karena itu, perlu adanya peningkatan kinerja dalam pelayanan demi memenuhi kepuasan pengguna fasilitas.

Kesenjangan terjadi apabila konsumen mempersepsikan pelayanan yang diterimanya lebih tinggi daripada desired service atau lebih rendah daripada adequate service kepentingan konsumen tersebut. Nilai kesenjanganmerupakan selisih antara skor indeks kinerja dan indeks kepentingan setiap variabel yang menggunakan rumus sebagai berikut:

$$
\text { Nilai Gap }=\text { Tingkat Kinerja }- \text { Tingkat Kepentingan }
$$


Kesenjangan terjadi apabila pelayanan yang diterima pada tingkat kinerja sama atau lebih kecil nilainya dari tingkat kepentingan sehingga selisihnya nilainya sangat rendah dan memperoleh kategori tidak puas.

\section{Kesimpulan}

1. Standar mutlak fasilitas fungsional Pelabuhan Perikanan Pantai (PPP) tipe C berdasarkan Permen KP Nomor PER.08/MEN/2012 terdiri dari 23 unit fasilitas fungsional. Fasilitas fungsional yang tersedia di Pelabuhan Perikanan Pantai (PPP) Bacan hanya terdapat 13 unit (63\%), dan dalam kategori baik dengan kondisi layak pakai hanya 10 unit (76,92\%). Untuk itu perlu dilakukan perbaikan dan peningkatan kelengkapan fasilitas fungsional agar sesuai satandar.

2. Tingkat pemanfaatan fasilitas fungsional dari 10 unit parameter penggunaannya sudah maksimal mencapai $100 \%$. Sedangkan dari tingkat kepuasan fasilitas fungsional mencapai $83 \%$ atau kategori puas. Untuk itu perlu terus dilakukan peningkatan kualitas kinerja dan pelayanan terhadap pengguna (steakholders) di PPP Bacan terhadap penggunaan fasilitas fungsional.

\section{Daftar Pustaka}

Aryani, D. Rosinta, F. 2010. Pengaruh kualitas layanan terhadap kepuasan pelanggan dalam membentuk loyalitas pelanggan.J.Administrasi dan Organisasi. 17(2): 114-126.

Atharis, Y. 2008. Tingkat Kepuasan Nelayan Terhadap Pelayanan Penyediaan Kebutuhan Melaut di Pelabuhan Perikanan Samudra Bungus Sumatra Barat.Skripsi.IPB. Bogor.

Ditjen Perikanan Tangkap. 2002. Pedoman pengelolaan pelabuhan perikanan. Jakarta keputusan menteri pendayagunaan aparatur negara nomor : Kep/25/M.Pan/2/2004 tentang pedoman umum penyusunan indeks kepuasan masyarakat unit pelayanan instansi pemerintah.

Guswanto, B. Gumilar, I. Hamdani, H. 2012. Analisis indeks kinerja pengelola dan indeks kepuasan pengguna di pelabuhan perikanan samudera Nizam Zachman Jakarta.J.Perikanan dan Kelautan. 3(4): 151-163.

Irawan, N. 2006.Analisis kepuasan mitra pembiayaan koperasi Baitul Maal Tadbirul Ummah.Skripsi.Departemen Ekonomi dan Manajemen.Institut Pertanian Bogor. Bogor.

Kusumawati, P. 2010. Upaya peningkatan kinerja usaha perikanan peningkatan lingkungan usaha pada alat tangkap cantrang (boat seine) dan kebijakan pemerintah daerah di kabupaten Rembang.J.Pemanfaatan Sumberdaya Perikanan Fakultas Perikanan dan Ilmu Kelautan. Universitas Diponegoro.

Lubis, E. 2006. B. Pengantar pelabuhan perikanan. Departemen pemanfaatan sumberdaya perikanan, Fakultas perikanan dan ilmu kelautan, Institut Pertanian Bogor.

Lubis, E. 2011.Kajian peran strategis pelabuhan perikanan terhadap pengembangan perikanan laut.J. Sumberdaya Perairan Akuatik. 5(2): 1-7.

Soamole, B. Bendiktus, S. 2013. Analisis presepsi penumpang terhadap kualitas pelayanan angkutan laut di pelabuhan regional Sanana kabupaten Kepulauan Sula. Maluku Utara. J. Teknik Sipil. 12(3): 201-209. 
Supranto, J. 2011. Pengukuran tingkat kepuasan pelanggan untuk menaikkan pangsa pasar. Jakarta. Rineka Cipta.

Walpole, R. E. 1997. Pengantar statistika.PT. Gramedia Pustaka Utama.Jakarta, 48.

Widiastuti, Ari. 2010. Kinerja Operasional Pelabuhan Perikanan Samudera Nizam Zachman Jakarta.Skripsi.IPB Bogor. 